\title{
Exploring pervasive displays for cemeteries and memorial sites
}

\author{
Jonna Häkkilä ${ }^{1} \cdot$ Ashley Colley $^{1}$ (D) * Matilda Kalving ${ }^{1} \cdot$ Meri-Tuulia Forsman $^{1}$
}

Received: 26 August 2019 / Accepted: 17 December 2019 / Published online: 11 January 2020

(C) The Author(s) 2020

\begin{abstract}
This paper addresses graveyards as a context for designing interactive technology, especially pervasive displays and the presentation of information related to graves and the dead. We present our research containing three user studies: a focus group-based study on perceptions of different display technologies in the cemetery context, evaluation of a gravestone display prototype, and a user study with a graveyard navigator prototype. Whereas, HCI research surrounding death has so far largely focused on an individual's digital remains, our focus is on the physical graveyard setting. We contribute to understanding the potential impacts and opportunities of interactive technology in this design context. Our salient findings highlight the cultural sensitivity and importance of dignity related to the context, unobtrusiveness of the technology, and concerns for privacy and social acceptability. Concepts taking into account these design aspects were of interest for those researching family histories, and visitors seeking improved navigation for the graveyard.
\end{abstract}

Keywords Graveyard $\cdot$ Cemetery $\cdot$ Death $\cdot$ Family histories $\cdot$ Remembrance $\cdot$ Cultural heritage $\cdot$ Pervasive displays . User experience

\section{Introduction}

Digital technology has integrated with most aspects of our everyday lives and is driving changes to conventional habits and traditional practices. It is expected that also domains which, so far, are not part of the core of digitalization will be increasingly touched by technology in the future. Rituals related to death are one such area, where practices of remembrance and mourning are changing [40]. In particular, there is much discussion on the "digital afterlife," addressing issues such as postmortem social media messages [12] and inheritance of digital remains [36]. Some presented digital solutions target new forms of remembrance, e.g., preserving a person's digital remains through a Facebook memorial site. Other approaches, such as Eternime [20] aim to create digital avatars of the dead that relatives can interact with. The topic has also been addressed through science fiction, e.g., Black Mirror 'I'll be right back' [1] and Real Humans [6].

In parallel with discussions on the digital afterlife, traditional physical cemeteries and graveyards are facing

Ashley Colley

ashley.colley@gmail.com

1 University of Lapland, Rovaniemi, Finland challenges of space limitation and lack of interest from younger generations. For example, burial along motorways has been proposed as a solution to address the lack of space in graveyards [5] and vertical skyscraper cemeteries are emerging in large cities globally. Current digital solutions that have been presented in the graveyard domain, such as screens embedded in gravestones showing videos of the deceased [24, 39] seem to discard the emotional, cultural, and historical importance of the graveyard. With pervasive displays invading different spaces of our everyday life $[8,12,28,31]$, graveyards are still locations with little embedded technology, and a novel context to investigate.

Graveyards are places of remembrance and mourning, but also sites of cultural heritage and family histories. How can we design digital technologies, which maintain the essence of the user experience when visiting a graveyard, but take an advantage of digital technologies to make the graves more accessible present richer content? Our research is motivated by the aim of offering more information about the dead, better access to remote or half-forgotten graves, and improving the visitor navigation in graveyards. We chart user perceptions of different design concepts to explore the social acceptability and perceived usefulness of the technology, and explore the design space of interactive technology at graveyards.

In this paper, we consider graveyards as a design context, and explore how interactive technology, especially 
pervasive displays, could be integrated into the graveyard visitor experience. We present our research on the topic, including three user studies and two prototypes, a gravestone display and graveyard navigator, and investigate visitors' perceptions of various concepts. This paper revisits our previous work on digital integration to graveyards $[25,26]$, adding an additional focus group-based study on perceptions of pervasive displays in the graveyard context. Through this combination, the prior findings are discussed in a more holistic way, exposing general themes related to this sensitive application domain.

\section{Related work}

\subsection{Graveyards as context for $\mathrm{HCl}$ research}

Whereas, graveyards have mostly gained attention from the domain-focusing cultural history viewpoint, the context has also been addressed by some human-computer interaction (HCI) researchers and practitioners. Prior HCI research has explored digital solutions for connecting visitors with the past $[18,19]$. In a playful example, Crow et al. implemented a location-based ghost hunting game, based on local history [19]. Interestingly, the digital game play elements were encased in small wooden coffins, adding to the ambience of the experience. As part of the meSch project, Ciolfi and Petrelli [18] presented concepts such as a digital guide book and augmented reality (AR) binoculars to provide graveyard visitors with more informed experiences. The future cemetery project in Bristol, UK, utilized projection on objects within the cemetery, focusing more on artistic and cultural heritage aspects than individual mourning [3].

Digital augmentation of gravestones is also emerging. Concepts adding content via smartphone-readable QR codes have been demonstrated [15, 24]. A variety of concepts for gravestones with embedded digital displays has also been presented by commercial organizations, ranging from embedding small tablets [39] to large 48" interactive screens [4] (Fig. 1, left and center). Driven by the limited availability and high costs of burial sites in some Asian cities, commercial organizations are now offering graves in virtual cemeteries [7] (Fig. 1, right). Another approach provides a communal memorial site, where the deceased are represented by glass Buddha statues, which relatives may visit using a smart access card [2].

In contrast to prior academic works set in graveyard contexts, which have primarily targeted cultural heritage experiences, we aim to focus on the grave itself as the site for physical remains. Although a variety of commercial concepts for augmenting the grave have been demonstrated, or are even deployed in isolated cases, there has so far been little study on visitor experiences related to such installations.

\subsection{Interactive concepts for remembrance and death}

When conducting research on interactive technology related to graveyards, it is also relevant to review more general research related to interactive technologies and death. A main focus of research on death in the HCI domain has been towards handling digital remains after an individual's death [32, 37]. Massimi et al. explored how digital artefacts left behind postmortem are used by loved ones as tools for remembrance, highlighting a number of unaddressed problems [32]. Focusing on social media, Brubacker et al. [11] review issues related to inheritance and the legacy contact approach employed by Facebook on memorial pages. It has also become easier for people to plan their own death and create services for their remaining loved ones [27, 29]. Jamison et al. investigated postmortem messages that are delivered after the sender's death [29], while Hall et al. presented a concept to publish digital memories at the locations the content was created [27]. Also, ambient
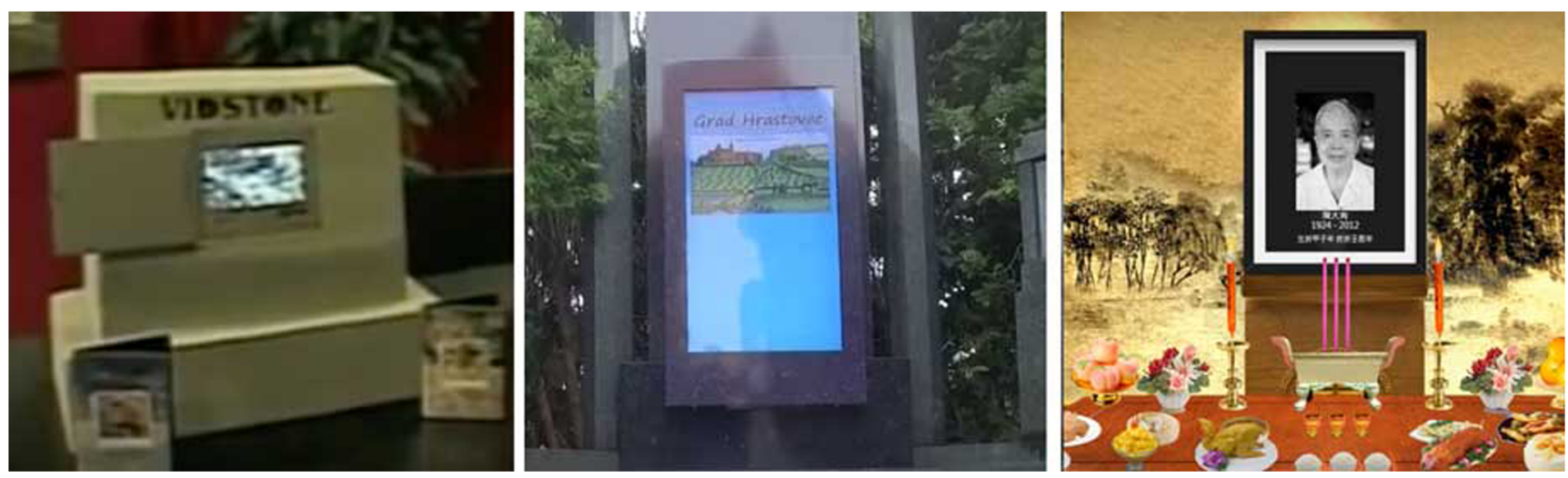

Fig. 1 Examples of commercial gravestone display concepts. Left/center: OLED displays embedded in gravestones. Right: gravestone in virtual world 
displays have been applied for remembrance. For example, as an ephemeral remembrance installation, where lighting a candle triggers photos of a past family member to appear in the background [38], or the Penseive Box, which illuminates on the dates of special occasions shared with a deceased loved one [16].

By situating our work in the context of a physical graveyard, the site of the physical remains of the deceased, we potentially expose a range of context-based experiental aspects that are not present in prior works set in the digital domain, or home environments.

\subsection{Navigation guides for cultural heritage}

In our research, we also address navigation within the graveyard and search of information about graves. There have been numerous prior works exploring navigating historical cultural heritage sites, one of the earliest being the location-aware tour guide GUIDE [17]. In the indoor museum context, Weker et al. highlight that the navigation goal in such contexts is not to get to the selected destination as quickly as possible, but to provide the opportunity to enjoy other exhibits along the way [41]. This driver is further addressed by Baker and Verstockt [9], who present a thematic routing algorithm to create a route optimized to encompass the most interesting points of interest. Other prior works in the area include, e.g., a multimodal mobile UI for guiding un-supervised visits to an archaeological site [33], and an audio-based mobile guide for experiencing Nottingham's historical riots [21].

Compared to prior works on cultural heritage site navigation, our graveyard navigation application exploration brings with it different user requirements. For example, many graveyard visitor's sole interest is to access a specific grave, and they have little interest in diversions to other points of interest. Further, while use of mobile devices, e.g., to take photographs, is nowadays an acceptable practice in the majority of museum sites, we aim to explore the acceptability of such devices as navigation aids in the graveyard context.

\section{Focus group on display concepts for a graveyard}

\subsection{Method}

To gain an overview of opinions to the topic of digitizing graveyards, we assembled a focus group. The focus group consisted of 5 people ( 2 female) and was recruited from the university of Lapland's study participant pool. Participants first completed study consent and background questionnaires. The moderator then introduced probe images showing digital graveyard concepts one at a time and guided discussion to explore participants' thoughts, feeling, and ideas related to the concepts.

The participant's ages were in the ranges 18-25: 1 person, 36-45: 2 people and 46-60, 2 people. Two participants visited graveyards 4-10 times per year, two 13 times per year, and one participant less than once a year. The most common reason for visiting the graveyards were remembrance of relatives or friends (4/5 participants) and lighting candles or taking flowers (3/5). Other reasons for visiting were taking a peaceful walk (1/5) and attending a funeral (1/5). Two participants revealed that long travel distances to family graves were a factor preventing more frequent visits. Almost all the participants noted an interest in family history (4/5).

\subsection{Digital graveyard image probes}

Nine images depicting digital display technology integration into graveyards were mocked up to use as probes in the focus group discussions (Fig. 2). The presented content included as follows:

(A) Interactive digital map signage at the entrance to a graveyard, e.g., enabling search for graves

(B) A dynamic navigation sign, guiding to a specific grave, e.g., row marker

(C) A digital gravestone able to change the deceased's name to suit the visitor, with the aim of improving access to distant relatives' graves

(D) A digital gravestone showing a photograph of the deceased

(E) A digital gravestone showing the deceased's family tree

(F) A digital gravestone showing a digital visitors book/social media view/artificial intelligence (AI) representation of the deceased

(G) A digital memorial display in a park that displays the visitors' own relative

(H) A family grave with family members represented by (digital) plaques

(I) An indoor digital memorial display that displays the visitors' own relative

\subsection{Results}

Digital signage and navigation Generally, the participants identified with the need to provide navigation guidance to find graves, particularly when visits to the graveyard were infrequent. For example, stating, "There is a need for that. I have some familiar graves I go to, but I know that in the same area of the cemetery, there are other graves I want to visit, but it's kind of haphazard to find them. If I 

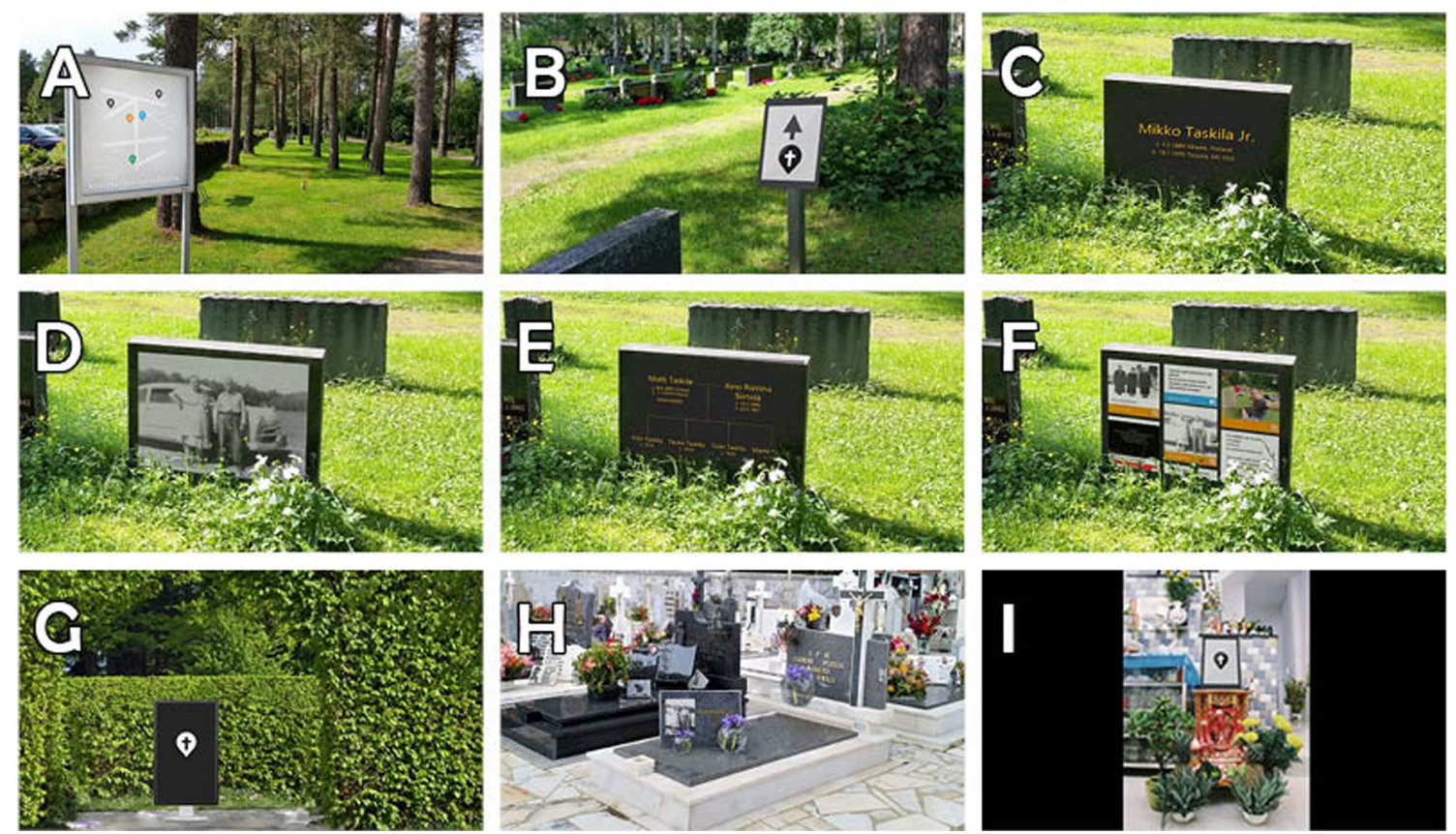

Fig. 2 Probe images used in the focus group

could search a name that I'm looking for, it would be a pretty big step forward" (Participant 2). It was noted that the interactive signage format could only support one user at a time, and smartphone-based navigators were proposed as a better solution supporting step-by-step guidance directly to the desired grave e.g., "...if you have a phone you can just follow the map. But here (with info sign) you only get (to view) the area, and you still have to search" (P1).

Based on interaction with the digital map signage, participants ideated a concept of showing a lighted route to the searched grave, "Could it light a path? That could help you to find the grave." (P5). Key concerns here were that digital solutions such as tablet displays would impact the sanctity of the graveyard. Participants considered that their light-path concept could address this, "The light path could be dimmed and restrained, so it would stay dignified" (P1). Issues of potential vandalism of installed digital infrastructure were also raised.

Digital gravestones Several participants questioned the importance of the physical remains in remembrance, suggesting, e.g., that common areas for lighting remembrance candles at graveyards enabled them to remember and respect the memory of the deceased. Considering current graveyards, problems with overcrowding and the limited availability of burial places were noted. Participants also highlighted that maintenance of a physical grave can become a burden to the living, one participant commenting on her family situation "Taking care of it has become a job [...] She (the deceased mother) doesn't require anything, but they have created a burden for themselves" (P5).
The display of photos on a digital gravestone was generally considered "Tacky" (P4). The concept was felt to degrade the status of the graveyard as a sacred place. Both the public display of photos and the family tree on gravestones raised discussion around privacy issues, with anyone able to see the displayed content. The participants noted that the display of images may have cultural differences (our source image for probe $\mathrm{H}$ was taken from Portugal, where the practice is common).

Feelings related to the display of a digital visitors book/social media view on the gravestone (F) raised similar privacy issues as the display of images. One participant suggesting that the current anonymity when leaving messages on graves is part of the ritual, “...messages left on graves are candles or flowers, that you don't know who they are from" (P2). Issues of requiring maintenance to ensure the digital content is updated were noted as placing a burden on the living relatives (P1). The possibility of discussing with an AI representation of the deceased at the graveside was unpopular, participants preferring to reflect on their memories of those passed away. One participant commented, “..if I would hear voices I would rather keep them in my own mind, not hear them from a stone" (P3).

Digital memorials Participants felt that digital memorial areas, either outdoors or indoors, had some positive elements, particularly for non-religious remembrance. However, some questioned the reason to visit an arbitrary memorial location: "I don't see any reason to go and remember him in a place where we have no common memories" (P5). Similarly to digital gravestone displays, 

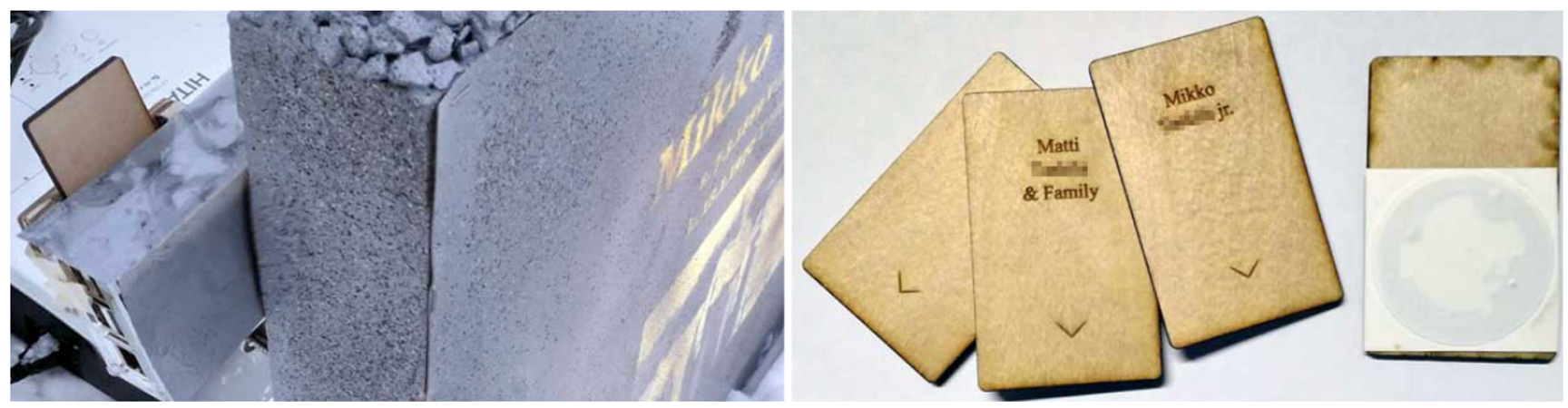

Fig. 3 Closeup of the RFID tag reader integrated into the gravestone and examples of the wooden cards used to trigger display content

risks of undermining the dignity of the deceased were raised, e.g., "If there is a slideshow running, it easily goes on the tacky side" (P4).

\section{Interactive gravestone display}

To further explore the concepts in our focus group study related to displaying information on the gravestone itself (Fig. 2 concepts $\mathrm{c}-\mathrm{g}$ ), we created and evaluated a prototype gravestone display.

\subsection{Concept and prototype}

The gravestone display concept aimed to address two use cases, (1) displaying additional content related to an individual's grave and (2) a "shared display" able to present information on different deceased, e.g., depending on the visitor. Rather than simply embedding a screen in a gravestone, we aimed to understand the potential for integrating a display into a gravestone such that it is not perceived as being a digital display screen. Hence, our implementation utilized back-projection on a screen modeled to look like a gravestone.

Interaction with the gravestone display was though RFID-based cards (Fig. 3, right), each representing a deceased individual and triggering the display of associated content. The prototype functionality was implemented using a Raspberry $\mathrm{Pi}$ and a RFID reader board which were attached to the gravestone (Fig. 3, left). To act as probes for opinion and ideation, a variety of traditional and exploratory content was designed (Fig. 4).

- Gravestone text (Fig. 4 Aa)
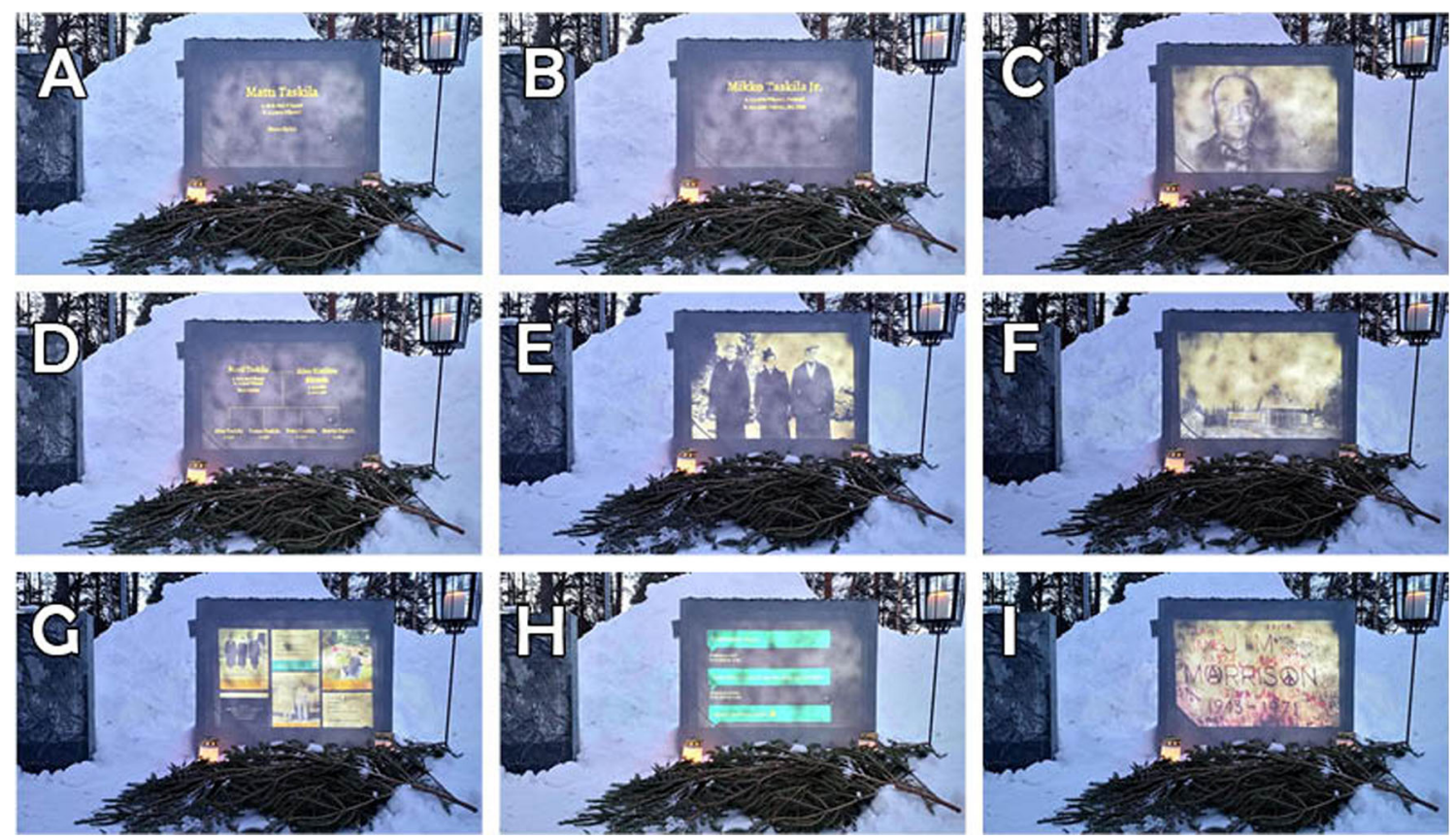

Fig. 4 The set of probe display content used in the user study 
- Text with photo

- Person 2 text (b), photo (b), family tree (d), photo of his children (e), photo of his house (f); views circulating

- Visitor book view (1) on-site visitors, (2) remote people's entries, and (3) a chat window to interact with an AI representation of the deceased $(\mathrm{g}, \mathrm{h})$

- Gravestone of a famous person (i)

\subsection{Prototype evaluation}

To support explorative evaluation of our concept, we situated our digital gravestone in a mockup graveyard in the grounds of the university that resembled a local graveyard. A focus group was assembled to provide feedback on the presented concepts. After completing consent and background questionnaires, the group were assembled around the gravestone and each content image (Fig. 4ai) was presented and discussed in turn. At the end of the session, participants completed an end questionnaire.

Eight participants (4 female) were recruited from the university, in the age groups 18-25: five people and 2635: three people. The most common reasons the participants visited a graveyard were (1) remembrance of relatives and friends $(8 / 8),(2)$ to light a candle or bring flowers $(4 / 8)$, (3) interest in historical environments (3/8), and (4) because graveyards were peaceful places for walking (3/8). Seven out of eight stated that they were interested in family history. None of the participants in this study participated in the other studies presented in this paper.

\subsection{Results}

Design and lifetime Participants felt that the design and style of a digital gravestone should be dignified and respectful, giving an impression of value, and something that is long-lasting, e.g., stating "The traditional tombstone has dignity when it is engraved." (Participant 7). However, it was felt these qualities were lacking in the presented prototype. Concerns about the lifetime of the digital artifact were also expressed, "A gravestone is forever, even if the city collapses, but this won't last forever" (P2), and concerns of malfunctions were verbalized: "What if it doesn't work when someone goes there, and they leave disappointed?" (P3).

Gravestone content The participants felt that interaction with the interactive gravestone should respect the slow pace and peacefulness of the context. For example, the feeling of a "slide show" of images was not considered suitable. The displayed photographs were commented in both positive and negative senses, e.g, "If it's a memorial stone, the picture suits it. Personally I don't like gravestones that have a picture on them" (P7) and "They are less dignified" (P5).
While in the positive sense, "But to that (digital gravestone) it kind of suits, because it's not a real grave" (P6). It was also considered that gravestone photographs would support children connecting with their deceased grandparents. The family tree content was considered interesting, but not suited to display on the gravestone itself, "...this might be a nice addition, but it doesn't suit a gravestone" (P7).

Display location Although participants saw value in the concept, it was generally commented that the gravestone itself was not the preferred location for the digital content. Instead, separate memorial spaces were suggested, e.g., "Does it have to be a gravestone? How about if it was like the memorial stones where people go to put candles for people who have been buried far away?" (P1). A memorial room was also suggested, ".... shelter attached to the graveyard where there is a (digital) placard for graves that are located in other graveyards" (P5).

Visitor book and Al chat The visitor book concept was generally disliked, with participants concerned about inappropriate messages being left on the gravestone, e.g., "Think about people walking through the graveyard drunk at night, writing messages" (P6). Participants rather favored smartphone-based concepts, accessible for relatives only, "....a site or app where you could sign a private guestbook. Maybe it could be open for relatives only" (P1).

The concept of an AI representing the dead person and answering visitors' messages was considered hilarious and provoked laughter. The idea was seen as absurd, and even if realized, not belonging to the graveyard context. The effect on mourners was also considered, "Can the family and relatives let go of the person, if it writes back?" (P1). Interestingly, the concept was also felt negative for the deceased, "Isn't it unethical to put it (the personality of the dead) in a gravestone, so it would never get away again?" (P5).

\section{Graveyard navigator}

To address challenges with locating graves in large graveyards, we designed and developed a location-aware graveyard navigator mobile application prototype [26].

\subsection{Graveyard navigator prototype}

The main target of the graveyard navigator was to enable a visitor to find a particular grave from a name search and then guide the user to walk to the grave's location. A secondary feature was to highlight family connections between graves, i.e., connecting parents, children, and siblings. The graveyard navigator app was implemented 
in unity and built for Android smartphones and tablet devices. The application included basic navigation features, a cursor marking the user's current position and heading and the possibility to manually zoom and rotate the map via touchscreen gestures (Fig. 5). Google maps was used as the source for general mapping data, and a more detailed map of the graveyard area was overlaid. Graves were marked by simple POI indicators, including the name and dates of birth and death of the deceased.

\subsection{Evaluation of the graveyard navigator}

To evaluate our prototype navigator and gain insight to the user perceptions on technology use at graveyards, a user study was conducted in an authentic use context, at a graveyard in Rovaniemi, Finland. The study participants were recruited at the graveyard location, near the entrance gates. After completing a short background questionnaire, the study consisted of a semi-structured interview, conducted while walking around the graveyard. As part of the interview, participants used the graveyard navigator to search for a grave by entering a name, and then walk to the grave using the system to navigate. As a second task, participants explored the family tree feature of the application, highlighting the relationships between those buried in the graves.

Twelve participants ( 7 female) took part in the study. Three of the 12 were between 20-29 years, 1/12 4049 years, 2/12 50-59 years, and 6/12 more than 60 years old. The participants represented different occupations, being graveyard workers (2 participants), other employment (3), pensioners (5), or students (2). Four of the 12 participants visited a graveyard weekly, 3/12 monthly, 4/12 a few times a

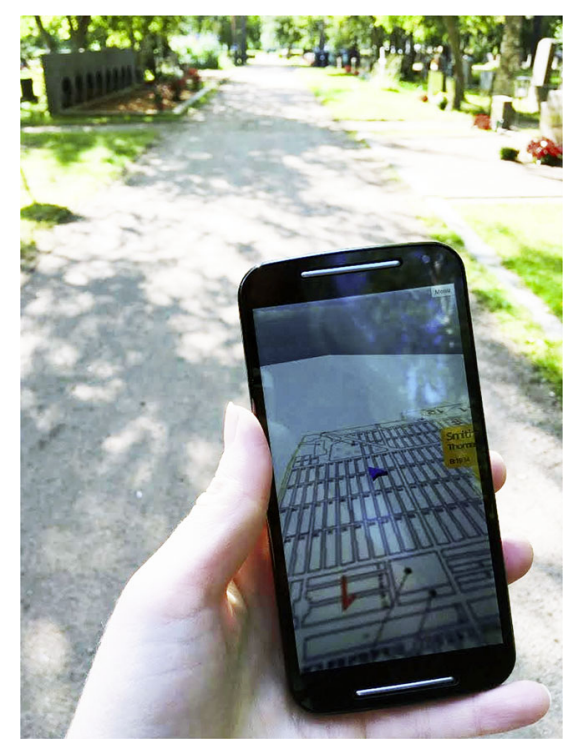

Fig. 5 Graveyard navigator prototype year, and 1/12 less. Two participants regularly visited more than four different graveyards, and 10/12 one or two. 11/12 had previously visited the graveyard where the interview took place and had relatives buried there. 5/12 reported having had difficulties, sometimes or often, finding a certain grave.

\subsection{Results}

Reasons for visiting the graveyard Based on the interviews, three different visitor types were identified, routine visitors, sacred dwellers, and explorers, each having a different relationship with the graveyard. Routine visitors were regular visitors to graveyards, conducting tasks such as tending flowers and looking after their relatives' graves as a normal "family routine." Routine visitors typically knew their graveyard(s) quite well, although even they did not know or remember all the details. Additionally, the graveyard workers we interviewed belonged to this category. For sacred dwellers, visiting a graveyard was a ritual used for meditation and for reflection and remembrance. For them, the atmosphere was the most important part of the visiting experience, "The graveyard is a sacred place, even the gravestones are sacred" (P10). Explorers interest in graveyards was for historical or cultural reasons, e.g., "I like the stories that gravestones bring to my mind. I like to walk around in graveyards. I often visit graveyards even on vacation trips" (P7).

Finding a grave Even before the interview had commenced, some participants mentioned they have had difficulties navigating in the graveyard. One participant had been trying to find a certain grave for 5 years before finding it, "We have had to look for our relative's grave for five years before finding it. It was really difficult to find, especially in winter" (P4). After testing the prototype, all considered the application useful with motives such as finding the grave of their great grandmother or just investigating the graveyard for curiosity. The graveyard workers interviewed were especially enthusiastic about the application, describing how they were asked for directions on a daily basis. However, they also had usability concerns about a mobile app, "Especially old people have trouble finding graves, but they usually don't have smartphones" (P2).

Family tree feature While the navigation guidance was welcomed as a solely positive feature, the family tree feature was perceived less so. Altogether, 9/12 of the interviewed participants felt they would be interested in the family tree function, e.g., "In my family they have been doing genealogy for tens of years. The app [with the family tree feature] would have helped" (P10). The remaining 3/12 participants were not interested in the family tree feature, 
suggesting the feature invaded the privacy of others by searching their family history.

\section{Discussion}

Several common themes emerged from the three conducted studies. These themes related to the sensitivity and private nature of the design context, and also to practical aspects related to visiting graves.

\subsection{The importance of dignity}

Perhaps the most important factor brought up throughout our studies was the need for dignity in design for the graveyard context. This applies both at the conceptual and physical level of the technology and applications. Especially graves, and any representations of graves, should be treated as respected objects. Our study participants unanimously agreed that graveyards were places where the atmosphere was important, where the dead, their memory, and their rest was to be respected. Our findings indicate that any digital implementations in this domain need to uphold the values and characteristics of traditional designs, e.g., dignity, calmness, and perceived longevity in materials, especially in gravestones. This applies to all aspects of the design and content, for example, even the visual transitions between different content views need careful design. Even though we focused on the outlook and design of our interactive gravestone prototype to ensure its fit to context, this was not sufficient. Finding an ideal combination of traditional, tangible, and intangible design, elements will require more exploration and iterations.

Here, we note that our findings are grounded in the the strongly Lutherian death culture of Finland [14]; the location of our research. Other cultures' differing views surrounding death may present highly differential views on our presented concepts. For example, displaying photographs of the deceased on graves is typical in Portugal, whereas in Aboriginal Australian culture, even the name of the deceased may not be mentioned for a long period of time after death and images would cause serious offense [34]. This further contrasts with the celebrations of the Mexican Day of the Dead, where private altars are constructed and the deceased awaken to join the celebrations.

\subsection{Pervasive displays at the graveyard}

Our study participants' perceptions on pervasive displays at the graveyard also reflected the general design requirement for respectful and dignified style. Unobtrusive design needs to be highlighted both in the form factor and content presentation of displays. Graveyards were recognized as public places, and providing personal or family information that is visible for all visitors was considered questionable on privacy grounds, and for some parts, also impractical. It should also be noted that graveyards attract different types of visitors, and the needs for routine visitors, sacred dwellers, and explorers (as we characterized them in Section 5.3) are somewhat different. Still, the preference for unobtrusive technology design and use was common across the different visitor groups.

Situating memorial displays provoked much discussion in our studies. Whereas, photos and family history information were perceived as interesting, the participants did not favor the idea of displaying this information on a grave itself. The possibility of presenting additional information was envisioned to fit better to an additional memorial, either next to the gravestone or as a separate installation or room, rather than on the gravestone itself.

\subsection{Opportunities for technology integration}

Whereas, our studies identified several requirements and concerns for integrating technology in a graveyards context, opportunities for digital technology were also identified. Adding photos related to the deceased person and old family history was felt to make the visiting experience more personal. Additional information was especially desired in the context of cemeteries crowded with the dead, where each of the deceased has only a small plaque. Knowing more information on distant relatives was generally perceived interesting, and additional information, especially old photos, were seen as an opportunity to facilitate connection across different generations. The participants' comments indicated that this content was found especially interesting and socially more acceptable when the deceased person represented an era that was long passed.

Technology can also assist in practical aspects related to remembrance. Navigating in the graveyard and finding a certain grave was reported as difficult by several participants, and, e.g., graveyard workers told how they received requests for guidance on a daily basis. Indeed, the graveyard navigator prototype was generally positively perceived by all the study participants. Another aspect where digital technologies may provide new opportunities is in easing the burden to tend old family graves. The tradition of taking care and remembering the dead through tending the graves can be an important family tradition, but in practice is difficult, e.g., due to long distances and aging visitors. This opportunity for digital technology and design should be further explored.

In the era of social media, online environments have become new sites for mourning [13]. Our studies also reflected this development and the participants considered some concepts to be a better fit to the existing digital 
world. Considering our concept of a gravestone-based digital guestbook, participants predominantly suggested ideas resembling existing solutions and practices in the online world, e.g., in Facebook, rather than integrating this type of service in a graveyard context. Especially the idea of allowing public comments was not appreciated in the graveyard context, where it was emphasized that the comments should be respectful, and hence require moderation. This dichotomy between the public and private nature of graveyards and their rituals has also been noted in prior works on the practice of posting selfies taken at funerals to social media [23, 30]. Gibbs et al. [23] argue that such image sharing is indicative of a general shift away from formal rituals towards personalized informal practices. Focusing on online memorial sites, prior work has highlighted the influence of platform features on participation [35]. Also, it would be of interest to further study differences in perceptions of digital and physical graveyard designs, c.f. existing services that allow the creation of a virtual grave [7].

\subsection{Environmental concerns}

Pervasive displays have an ecological and carbon footprint in their production, use, and disposal. Additionally, introducing such devices to the natural graveyard environment brings particular challenges in their potential hazard to wildlife and contribution to light pollution. In the scope of media architectures, Foth and Amayo Caldwell [22] propose the inclusion of a non-human design persona, e.g., an insect or nocturnal animal, in the design process to ensure ecological issues are to the fore. As a guiding principle, designers should question if the impact of such media installations outweighs the negatives to render a net positive installation [10].

\subsection{Limitations and methodological notes}

We acknowledge that the internal validity of our research is limited by its small sample sizes. Additionally, we note the potential effect of age and religious belief, which were recorded but not controlled in our studies. The external validity and transferability of our findings is limited by the homogeneous cultural background of the participants, as the studies were conducted in the same geographical context. As noted in the prior sections, traditions related to the deceased and graves have wide cultural variation and the central issues of solitude and peace, which were raised by our study groups, may be of less relevance in other cultures. However, we believe our findings provide interesting insights to the under-explored area of integrating digital technologies with the rituals and contexts surrounding the deceased.
Methodologically, the sensitivity of the design domain was highlighted throughout the studies. We found that using the authentic context, i.e., a graveyard, was very important for the validity of the interviews. Also, we sought to take this into account when evaluating the gravestone display concepts through a prototype in a mock up graveyard context. As our findings exposed our study participants' sensitivities to the graveyard context, we believe our staged environment was to some degree effective in recreating the atmosphere of a real graveyard. 4

\section{Conclusion}

In this paper, we have explored perceptions towards integrating digital displays and navigation aids into the graveyard context. Based on or findings, design for the graveyard context should emphasize the dignity of the deceased and be long-lasting. This raises conflicts with digital solutions in general that typically follow current trends and, by their nature, rarely last for more than a decade. While the aim of concepts to enhance the experience of visiting a grave was appreciated, there was general agreement that this should not be located with the physical remains, i.e., not integrated with the gravestone. Privacy concerns were raised for concepts presenting additional media on the deceased in a public graveyard environment and solutions such as digital visitor books and AI-based chat with the deceased were considered unsuitable for the graveyard environment. The need for tools to assist navigation to specific graves was highlighted. Our studies also identified opportunities for digital technologies in facilitating families' cross-generation interaction and in supporting tending the graves, which should be explored more.

Funding information Open access funding provided by University of Lapland. The work has been partially supported by the European Union's Horizon 2020 Programme under grant no. 760973 DecoChrom, and by Business Finland as part of the VARPU project.

Open Access This article is licensed under a Creative Commons Attribution 4.0 International License, which permits use, sharing, adaptation, distribution and reproduction in any medium or format, as long as you give appropriate credit to the original author(s) and the source, provide a link to the Creative Commons licence, and indicate if changes were made. The images or other third party material in this article are included in the article's Creative Commons licence, unless indicated otherwise in a credit line to the material. If material is not included in the article's Creative Commons licence and your intended use is not permitted by statutory regulation or exceeds the permitted use, you will need to obtain permission directly from the copyright holder. To view a copy of this licence, visit http:// creativecommonshorg/licenses/by/4.0/. 


\section{References}

1. Black mirror - i'll be right back. https://www.imdb.com/title/ tt2290780/. Accessed: 2019-02-20

2. Death is a high-tech trip in Japan's futuristic cemeteries. https:// motherboard.vice.com/en_us/article/9a3a5a/death-is-a-high-techtrip-in-japans-futuristic-cemeteries. Accessed: 2019-02-20

3. Future cemetery. http://www.react-hub.org.uk/projects/heritage/ future-cemetery/. Accessed: 2019-02-20

4. Large screen grave. https://www.youtube.com/watch?v=vv99ER2 AlOM. Accessed: 2019-02-20

5. Motorway burial. https://www.theguardian.com/science/2019/jul/ 05/bury-bodies-along-uks-motorway-to-ease-burial-crisis-expertsuggests. Accessed: 2019-08-20

6. Real humans. https://www.imdb.com/title/tt4122068/. Accessed: 2019-02-20

7. Virtual reality cemetery. http://vrworld.com/2017/11/22/first-vrcemetery-solution-overcrowded-hong-kong/. Accessed: 2019-0220

8. Alt F, Kubitza T, Bial D, Zaidan F, Ortel M, Zurmaar B, Lewen T, Shirazi AS, Schmidt A (2011) Digifieds: insights into deploying digital public notice areas in the wild. In: Proceedings of the 10th International Conference on Mobile and Ubiquitous Multimedia, ACM, pp 165-174

9. Baker K, Verstockt S (2017) Cultural heritage routing: a recreational navigation-based approach in exploring cultural heritage. J Comput Cult Her (JOCCH) 10(4):24

10. Bendor R (2018) Sustainability, hope, and designerly action in the anthropocene. Interactions 25(3):82-84

11. Brubaker JR, Callison-Burch V (2016) Legacy contact: designing and implementing post-mortem stewardship at facebook. In: Proceedings of the $2016 \mathrm{CHI}$ Conference on Human Factors in Computing Systems, CHI '16. ACM, New York, pp 2908-2919. https://doi.org/10.1145/2858036.2858254

12. Brubaker JR, Hayes GR (2011) We will never forget you [online]: an empirical investigation of post-mortem MySpace comments. In: Proceedings of the ACM 2011 Conference on Computer Supported Cooperative Work, ACM, pp 123-132

13. Brubaker JR, Hayes GR, Dourish P (2013) Beyond the grave: Facebook as a site for the expansion of death and mourning. Inf Soc 29(3):152-163

14. Butters M (2017) Between east and west: a diachronic overview of finnish death culture. Death Studies 41(1):51-60

15. Cann CK (2013) Tombstone technology: deathscapes in Asia, the Uk and the US. In: Digital Legacy and Interaction, Springer, pp 101-113

16. Chaudhari C, Prakash A, Tsaasan A, Brubaker JR, Tanenbaum J (2016) Penseive box: themes for digital memorialization practices. In: Proceedings of the TEI'16: Tenth International Conference on Tangible, Embedded, and Embodied Interaction, ACM, pp 398-403

17. Cheverst K, Davies N, Mitchell K, Friday A (2000) Experiences of developing and deploying a context-aware tourist guide: the guide project. In: Proceedings of the 6th Annual International Conference on Mobile Computing and Networking, ACM, pp 20-31

18. Ciolfi L, Petrelli D (2015) Studying a community of volunteers at a historic cemetery to inspire interaction concepts. In: Proceedings of the 7th International Conference on Communities and Technologies, C\&\#38; ' '15. ACM, New York, pp 139-148. https://doi. org/10.1145/2768545.2768547

19. Crow B, Longford M, Sawchuk K, Zeffiro A (2009) Voices from beyond: Ephemeral histories, locative media and the volatile interface. In: Handbook of Research on Urban Informatics: The
Practice and Promise of the Real-time City, IGI global, pp 158 178

20. Eternime: http://eterni.me/. Accessed: 2019-02-20

21. Fitzgerald E, Taylor C, Craven M (2013) To the castle! a comparison of two audio guides to enable public discovery of historical events. Pers Ubiquit Comput 17(4):749-760

22. Foth M, Caldwell GA (2018) More-than-human media architecture. In: Proceedings of the 4th Media Architecture Biennale Conference, MAB18. ACM, New York, pp 66-75. https://doi.org/10.1145/3284389.3284495

23. Gibbs M, Meese J, Arnold M, Nansen B, Carter M (2015) \# Funeral and Instagram: death, social media, and platform vernacular. Information, Communication \& Society 18(3):255268

24. Gotved S (2015) Privacy with public access: digital memorials on quick response codes. Information, Communication \& Society 18(3):269-280

25. Häkkilä J., Colley A, Kalving M (2019) Designing an interactive gravestone display. In: Proceedings of the 8th ACM International Symposium on Pervasive Displays, PerDis '19. ACM, New York, pp 4:1-4:7. https://doi.org/10.1145/3321335.3324952

26. Häkkilä J, Forsman MT, Colley A (2018) Navigating the graveyard: designing technology for deathscapes. In: Proceedings of the 17th International Conference on Mobile and Ubiquitous Multimedia, ACM, pp 199-204

27. Hall A, Bosevski D, Larkin R (2006) Blogging by the dead. In: Proceedings of the 4th Nordic Conference on Human-computer Interaction: Changing roles, ACM, pp 425-428

28. Hosio S, Goncalves J, Kukka H, Chamberlain A, Malizia A (2014) What's in it for me: exploring the real-world value proposition of pervasive displays. In: Proceedings of the International Symposium on Pervasive Displays, ACM, p 174

29. Jamison-Powell S, Briggs $P$, Lawson $S$, Linehan $C$, Windle $K$, Gross H (2016) PS. I love you: understanding the impact of posthumous digital messages. In: Proceedings of the $2016 \mathrm{CHI}$ Conference on Human Factors in Computing Systems, ACM, pp 2920-2932

30. Kohn T, Arnold M, Gibbs M, Meese J, Nansen B (2018) The social life of the dead and the leisured life of the living online. Leisure and death, An anthropological tour of risk, death, and dying

31. Kostakos V, Ojala T (2013) Public displays invade urban spaces. IEEE Pervasive Computing 12(1):8-13

32. Massimi M, Baecker RM (2010) A death in the family: opportunities for designing technologies for the bereaved. In: Proceedings of the SIGCHI Conference on Human Factors in Computing Systems, CHI '10. ACM, New York, pp 1821-1830. https://doi.org/10.1145/1753326.1753600

33. McGookin D, Vazquez-Alvarez Y, Brewster S, BergstromLehtovirta J (2012) Shaking the dead: multimodal location based experiences for un-stewarded archaeological sites. In: Proceedings of the 7th Nordic Conference on Human-Computer Interaction: Making Sense Through Design, ACM, pp 199-208

34. McGrath P, Phillips E (2008) Australian findings on aboriginal cultural practices associated with clothing, hair, possessions and use of name of deceased persons. Int J Nurs Pract 14(1):57-66

35. Mori J, Gibbs M, Arnold M, Nansen B, Kohn T (2012) Design considerations for after death: comparing the affordances of three online platforms. In: Proceedings of the 24th Australian Computer-Human Interaction Conference, ACM, pp 395-404

36. Odom W, Banks R, Kirk D, Harper R, Lindley S, Sellen A (2012) Technology heirlooms?: considerations for passing down and inheriting digital materials. In: Proceedings of the SIGCHI Conference on Human Factors in computing systems, ACM, pp 337-346 
37. Odom W, Harper R, Sellen A, Kirk D, Banks R (2010) Passing on \& putting to rest: understanding bereavement in the context of interactive technologies. In: Proceedings of the SIGCHI Conference on Human Factors in Computing Systems, CHI '10. ACM, New York, pp 1831-1840. https://doi.org/10.1145/1753326. 1753601

38. Uriu D, Okude N (2010) Thanatofenestra: photographic family altar supporting a ritual to pray for the deceased. In: Proceedings of the 8th ACM Conference on Designing Interactive Systems, ACM, pp 422-425

39. Vidstone: https://www.youtube.com/watch?v=7Tvfny_rJmY. Accessed: 2019-02-20
40. Walter T, Hourizi R, Moncur W, Pitsillides S (2012) Does the internet change how we die and mourn? Overview and analysis. OMEGA-Journal of Death and Dying 64(4):275-302

41. Wecker AJ, Lanir J, Kuflik T, Stock O (2015) Where to go and how to get there: guidelines for indoor landmark-based navigation in a museum context. In: Proceedings of the 17th International Conference on Human-Computer Interaction with Mobile Devices and Services Adjunct, MobileHCI '15. ACM, New York, pp 789796. https://doi.org/10.1145/2786567.2793702

Publisher's note Springer Nature remains neutral with regard to jurisdictional claims in published maps and institutional affiliations. 